\title{
Surface Attachment of Active Antimicrobial Coatings Onto Conventional Plastic Based Laminates and Performance Assessment of These Materials on the Storage Life of Vacuum Packaged Beef Sub-Primals
}

D. Clarke

University College Cork, Ireland

A. Tyuftin

University College Cork, Ireland

M. Cruz-Romero

University College Cork, Ireland

See next page for additional authors

Follow this and additional works at: https://arrow.tudublin.ie/schfsehart

Part of the Food Science Commons

\section{Recommended Citation}

Clarke, D. et al (2017). Surface attachment of active antimicrobial coatings onto conventional plasticbased laminates and performance assessment of these materials on the storage life of vacuum packaged beef sub-primals. Food Microbiology, 62, pp.196-201. doi: 10.1016/j.fm.2016.10.022. E

This Article is brought to you for free and open access by the School of Food Science and Environmental Health at ARROW@TU Dublin. It has been accepted for inclusion in Articles by an authorized administrator of ARROW@TU

Dublin. For more information, please contact arrow.admin@tudublin.ie, aisling.coyne@tudublin.ie, gerard.connolly@tudublin.ie.

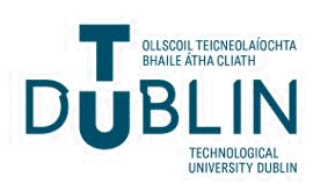




\section{Authors}

D. Clarke, A. Tyuftin, M. Cruz-Romero, D. Bolton, S. Fanning, S. K. Pankai, Carmen Bueno-Ferrer, Patrick Cullen, and J. P. Kerry

This article is available at ARROW@TU Dublin: https://arrow.tudublin.ie/schfsehart/293 


\title{
Manuscript Details
}

\section{Manuscript number}

Title

Article type
FM_2016_189

Surface attachment of active antimicrobial coatings onto conventional plasticbased laminates and performance assessment of these materials on the storage life of vacuum packaged beef sub-primals.

Research Paper

\begin{abstract}
Abstract Two antimicrobial coatings, namely Sodium octanoate and Auranta FV (a commercial antimicrobial composed of bioflavonoids, citric, malic, lactic, and caprylic acids) were used. These two antimicrobials were surface coated onto the inner polyethylene layer of cold plasma treated polyamide films using beef gelatin as a carrier and coating polymer. This packaging material was then used to vacuum pack beef sub-primal cuts and stored at $4^{\circ} \mathrm{C}$. A control was prepared using the non-coated commercial laminate and the same vacuum packaged sub-primal beef cuts. During storage, microbial and quality assessments were carried out. Sodium octanoate treated packages significantly $(p<0.05)$ reduced microbial counts for all bacteria tested with an increase of 7 and 14 days, respectively compared to control samples. No significant effect on $\mathrm{pH}$ was observed with any treatment. The results suggested that these food grade antimicrobials have the potential to be used in antimicrobial active packaging applications for beef products.
\end{abstract}

\section{Keywords}

\section{Corresponding Author \\ Corresponding Author's Institution}

Order of Authors
Gelatin; Coatings; Antimicrobials; Active Food Packaging; Plasma treatment Joe P. Kerry

UCC

David Clarke, Andrey Tiuftin, Malco Cruz-Romero, Declan Bolton, Seamus Fanning, S.K. Pankaj, Carmen Bueno-Ferrer, PJ Cullen, Joe P. Kerry

\section{Submission Files Included in this PDF}

\section{File Name [File Type]}

Cover letter journal for revision.doc [Cover Letter]

Answers to comments on paper corrected.docx [Response to Reviewers]

Manuscript.doc [Manuscript File]

Figures-corrected-Journall.doc [Figure]

Highlights and Title page.docx [Highlights]

To view all the submission files, including those not included in the PDF, click on the manuscript title on your EVISE Homepage, then click 'Download zip file'. 


\section{Abstract}

2Two antimicrobial coatings, namely Sodium octanoate and Auranta FV (a 3commercial antimicrobial composed of bioflavonoids, citric, malic, lactic, and 4caprylic acids) were used. These two antimicrobials were surface coated onto the 5inner polyethylene layer of cold plasma treated polyamide films using beef gelatin as 6a carrier and coating polymer. This packaging material was then used to vacuum 7 pack beef sub-primal cuts and stored at $4^{\circ} \mathrm{C}$. A control was prepared using the non8coated commercial laminate and the same vacuum packaged sub-primal beef cuts. 9During storage, microbial and quality assessments were carried out. Sodium 10octanoate treated packages significantly $(\mathrm{p}<0.05)$ reduced microbial counts for all 11bacteria tested with an increase of 7 and 14 days, respectively compared to control 12samples. No significant effect on $\mathrm{pH}$ was observed with any treatment. The results 13suggested that these food grade antimicrobials have the potential to be used in 14antimicrobial active packaging applications for beef products.

\section{5}

\section{Introduction}

17Microbial contamination has long been recognised as the main source of spoilage 18and reduction of meat quality (Kerry et al., 2012). Prolonging shelf-life, along with 19delivering a high quality food product in suitable flexible packaging, is essential in 20order to address issues such as, global supplier demands, economical profit, 21customer satisfaction, reducing packaging, and more importantly, reduction of food 22wastage. Smart packaging solutions presented in the form of antimicrobially-active 23packaging may be a solution, or part of a solution, to these and other issues (Kerry et 24al., 2008).

25Naturally-occurring active antimicrobial substances offer many potential benefits 26with respect to food packaging applications. Taken from natural food sources, 27potentially edible, and therefore food contact-friendly films and coatings offer new 28alternatives in relation to food packaging materials and packaging applications. 29Edible films and coatings have been used for preservation purposes and can be 30 formulated into active materials with the addition of antimicrobial substances (Cuq 31et al., 1995; Campos et al., 2011). 
32Bioactive edible/biodegradable films have limitations with respect to certain 33mechanical properties such as transparency, and printability issues. Therefore, such 34limitations mean that these materials will never compete in volume or scale with 35industrially-based conventional packaging materials for some time to come. 36However, the development of such materials should be encouraged as they would 37certainly present novel materials with niche roles and applications, especially when 38used in combination with conventional plastic-based packaging materials

39The use of gelatin to form edible films or coatings has been well documented since 40the 1960’s (Hanani et al., 2012a). Films formed using gelatin sources as a primary 41biopolymer packaging film are more desirable to manufactures as they are low cost 42and wide availability (Hanani et al., 2013). Gelatin has been shown to produce films 43with good transparency, mechanical and barrier properties, and can be manufactured 44by extrusion or casting processes (Hanani et al., 2012b, Hanani et al., 2013, 45Molinaro et al., 2015; Wang et al., 2007). There is increased interest in the 46development and use of edible packaging materials to preserve meat quality for 47longer storage periods, while at the same time, maintaining food safety based on 48consumer demands for natural and safe products (Cutter et al., 2006; Ortega et al., 492014). Polymeric matrices, as well as bioactive coatings and films, can be used as 50carriers for natural antimicrobials. This technique allows for slow diffusion of the 51antimicrobial agent from the packaging material, thus allowing a continuous 52antimicrobial effect on the food product surface over time (Han et al., 2014). This 53approach has been shown to be more effective than spraying, dipping or submerging 54products with or in solutions of antimicrobial agents (Lu et al., 2010, Muriel-Galet et 55al., 2012, Quintavalla \& Vincini, 2002, Suppakul et al., 2008 \& Yingyuad et al., 562006). Numerous publications have reported the effects of activating biopolymer57based materials with antimicrobial substances for packaging applications (Gómez58Estaca et al., 2010, Oussalad et al., 2004, Millette et al., 2007, Gill et al., 2002, \& 59Morsy et al., 2014) to name a few. However, limited studies on bovine gelatin as a 60polymer carrier of antimicrobial substances to reduce the microbial growth on fresh 61meat have been reported. Recently our group demonstrated the application of beef 62gelatin films with incorporated antimicrobials as active packaging. Four 63commercially derived antimicrobials namely, Articoat DLP 02 (AR), Artemix Consa 64152/NL (AX), Auranta FV (AFV) (a mixture of citric acid, malic acid, lactic acid and 
65caprylic acid in water) and Sodium octanoate (SO) were successively incorporated 66into beef-derived gelatine films and tested for structural, mechanical and barrier 67properties. It was shown that active antimicrobial agents could potentially serve as 68commercial antimicrobial coatings for application onto conventional plastic food 69packaging materials (Clarke et al. 2016).

70To the best of our knowledge, no studies have reported the effect of the use of cold 71plasma treatment to improve attachment properties of activated gelatin solutions 72containing antimicrobials, and the application of the developed coated materials to 73reduce the microbial growth and extend the shelf life of fresh beef sub-primals. 74Therefore, the objective of this study was to examine the effectiveness of surface 75attachment of active beef-derived gelatine antimicrobial (SO and AFV) coatings 76onto conventional commercial vacuum packaging laminates 77(polyethylene/polyamide) and assess the performance of these packaging materials 78on microbial counts of vacuum packaged beef steaks.

\section{Materials and methods}

\subsection{Materials, microbiological media and beef}

81Antimicrobials used in this study included SO, and AFV. SO was obtained from 82Sigma-Aldrich, UK and AFVfrom Envirotech Innovative Products Ltd, Ireland. 83Glycerol (KB Scientific Ltd, UK) was used as a plasticizer and Beef gelatin 100 84bloom (Helan ingredients, UK) was used as the basal material for all film matrices. 85Two beef subprimal striploins were purchased from a local beef supplier and were 86delivered at $4^{\circ} \mathrm{C}$ in vacuum-skin plastic packaging formats and used on the same day 87of delivery. Conventional vacuum polyamide/low density polyethylene (PA/LDPE) 88pouches (200x300 mm, water vapour transmission rate of $2.8 \mathrm{~g} / \mathrm{m}^{2} 24 \mathrm{hr}$ and oxygen 89permeabiltlty rate of $50 \mathrm{~cm}^{3} / \mathrm{m}^{2} 24 \mathrm{hr}$ ) were supplied by Cryovac (Sealed Air W.R. 90Grace Europe Inc., Lausanne, Switzerland) and used as industry standard materials 91for coating and meat packaging trials throughout these studies.

\subsection{Plasma treatment}

93In order to increase the hydrophilicity of the LDPE inner part of the PA/LDPE 94laminate vacuum pouches, cold plasma treatment was carried out on a Dielectric- 
95Barrier Discharge (DBD) plasma system prior to the application of the antimicrobial 96coatings.

97 Briefly, pouches of $200 \times 300 \mathrm{~mm}$ size were cut to size $170 \times 280 \mathrm{~mm}$ and the 98surface of the LDPE side of the laminate pouches were plasma treated at 99atmospheric pressure using atmospheric air. A schematic representation of the 100experimental setup is presented in Figure 1. The plasma source consisted of two 101circular aluminium plate electrodes (outer diameter $=158 \mathrm{~mm}$ ). The top dielectric 102barrier was Perspex dielectric barrier (10 mm thickness) and the bottom dielectric 103barrier was polypropylene sheet (5 mm thickness). When the potential across the gap 104reached the breakdown voltage the dielectric barrier prevented the arc transition and 105also homogenised the micro-discharges. The applied voltage was $80 \mathrm{kV}$ which was 106obtained from a step-up transformer (Phenix Technologies, Inc., USA) using a 107 variac. The input of $230 \mathrm{~V}, 50 \mathrm{~Hz}$ was given to the primary winding of high voltage 108step-up transformer from the mains supply. At the time of treatment, the atmospheric 109air condition was $45 \%$ relative humidity $(\mathrm{RH})$ and $22^{\circ} \mathrm{C}$. The samples were plasma 110treated for $60 \mathrm{sec}$ to cover the entire film area, leaving only approximately $5 \mathrm{~cm}$ from 111the edge of the film (high voltage electrode was placed $1 \mathrm{~cm}$ above the film).

112Plasma treatment was carried out on 60 different film samples. Following treatment, 113plasma treated samples were placed in zip lock plastic bags to protect films from 114antistatic environments and dust particles.

115Static contact angle (Theta Lite Optical Tensiometer, Biolin Scientific, UK) was 116measured before and after plasma treatment by the sessile drop technique. A drop of 117each test liquid (water or ethylene glycol) was uniformly placed on the film surface 118using a needle and the image recorded at 15 frames per sec for $10 \mathrm{sec}$. Images were 119analyzed using the OneAttension software (v 2.1). All values reported are the mean 120of more than 130 data points carried out in triplicate. Surface-free energy was 121calculated using the Owen-Wendt model, utilising the same software. Water and 122ethylene glycol were used as the test liquids.

123Plasma treated film samples were coated with water-based gelatine coatings 124containing the test antimicrobials. For plasma treated films, films were gelatine 125 coated after 30 hr of plasma treatment. 


\subsection{Coatings of edible antimicrobial films and packaging of beef}

\subsubsection{Preparation of film forming solutions and coatings}

128Gelatine film forming solutions were prepared according to the procedure outlined 129by Wang et al, (2007), with minor modifications. Briefly, dry beef gelatine was 130dissolved in distilled water $(5 \% \mathrm{w} / \mathrm{w})$ by heating at $90^{\circ} \mathrm{C}$ in a shaking water bath 131(SW23, Julabo USA INC., Allentown, PA, USA) for 30 min and glycerol was added 132under constant stirring at a concentration of 33\% w/w dry matter. Successively, the 133solution was cooled down at room temperature to $40^{\circ} \mathrm{C}$ before the addition of the 134antimicrobials. The antimicrobials were added at twice the minimum inhibitory 135concentration (MIC) determined for each of the two antimicrobials used (Clarke et 136al., 2016). The MIC of AFV and SO was previously determined at levels of 1.5 and $1371 \%$, respectively and added at a weight of $3 \mathrm{~g}$ and $2 \mathrm{~g}$ respectively (Clarke et al., 1382016). The solution was then stirred for 15 min using a sterile magnetic stirrer before 139casting onto levelled plasma-treated LDPE film surfaces using a Micron II film 140applicator (Gardco, FL, USA) and dried for $48 \mathrm{hr}$ at $20^{\circ} \mathrm{C}$. Gelatine coating thickness 141was measured using a digital micrometer - Käfer Digital Thickness gauge (Käfer 142Messuhrenfabrik GmbH \& Co., Villingen-Schwenningen, Germany) at 5 random 143locations of 10 random films for each sample treatment. The thickness of gelatine 144coating layer ranged between 11-15 $\mu \mathrm{m}$.

1452.3.2. Vacuum packaging of beef sub-primals using active antimicrobial coated 146laminate pouches

147Plasma-treated conventional PA/LDPE films coated with active gelatin-based 148coatings were detached from the flat surface on which they were coated, the edges of 149each laminate sample was cleaned with ethanol to remove unwanted residue. Each 150pack was heat-sealed to form a pouch $(170 \times 290 \mathrm{~mm})$ using Webomatic type D463 151(Webomatic Vacuum Packaging Systems, Werner Bonk, Mausegat 59, D 463 152Bochum 6, Germany) with the sealing time set at 2.5 s. In order to avoid adhesion 153between the coated films, sterile food grade aluminium foil was placed between the 154films prior to sealing.

155Beef striploins were cut into 90 steaks $(2.5 \mathrm{~cm}$ in thickness). A total of 30 steaks 156were individually vacuum packaged in AFV coated pouches, SO coated pouches or 
157non-coated pouches without plasma-treatment (control group), respectively using a 158Webomatic type D463 (Webomatic Vacuum Packaging Systems, Werner Bonk, 159Mausegat 59, D 463 Bochum 6, Germany) machine (20 sec vacuum process, $2.5 \mathrm{sec}$ 160heat-seal dwell-time). Vacuum packaged samples were stored under chilled 161conditions of $4^{0} \mathrm{C}$ in a walk-in chilled room and sampled at weekly intervals for up to 1625 weeks.

\section{4. pH}

164The $\mathrm{pH}$ of the beef steaks was measured using a digital $\mathrm{pH}$ metre (Mettler-Toledo $165 \mathrm{GmbH}$, Schwerzenbach, Switzerland) by inserting the glass probe directly into the 166beef steak. Each value represents the average of three readings.

\subsection{Microbiological studies}

168Microbiological analyses of beef steaks during storage at $4{ }^{\circ} \mathrm{C}$ were performed in 169triplicate on each measurement day. In order to obtain a representative sample, three 170steaks from each treatment were randomly selected for analysis. A total of $10 \mathrm{~g}$ from 171both the upper and bottom parts of the surface of the steak was aseptically taken 172using sterile forceps and scalpel, placed into a sterile stomacher bag (Seward, UK) to 173which $90 \mathrm{ml}$ of sterile Maximum recovery diluent (MRD) (Oxoid, UK) was added as 174an isotonic diluent and thoroughly mixed for 3 min using a stomacher (Seward, UK) 175in order to obtain a primary 10 -fold dilution. This was then 10 -fold serially diluted 176using MRD and used to enumerate total viable counts (TVC), psychrotrophic 177bacteria, total anaerobic bacteria (TAB), Lactic acid bacteria (LAB), total coliforms 178and Escherichia coli (E. coli).

179The TVC and psychrotrophic bacteria were enumerated in Plate count agar (PCA) 180plates (Oxoid, Basingstoke, UK) after incubation for $48 \mathrm{hr}$ at $30{ }^{\circ} \mathrm{C}$ or 7 days at $4^{\circ} \mathrm{C}$, 181respectively. Total coliforms and E. coli were enumerated on Compact Dry E.C 182plates (Nissui Pharmaceutical, Co. Ltd. Japan) $\left(20 \mathrm{~cm}^{2}\right)$ after incubation at $37^{\circ} \mathrm{C}$ for $18324 \mathrm{hr}$. LAB were enumerated on overlaid MRSA agar (Oxoid) after incubation for 3 184days anaerobically at $30{ }^{\circ} \mathrm{C}$ in anaerobic jars containing Anaerocult ${ }^{\circledR}$ (Merk). TAB 185were enumerated on Tryptone soy agar (TSA) (Oxoid) agar enriched with $0.6 \%$ yeast 186extract Oxoid (Basingstoke, UK) after 3 days incubation anaerobically at $30^{\circ} \mathrm{C}$ in 187anaerobic jars containing Anaerocult ${ }^{\circledR}$. Clostridium spp. were enumerated on 
188reinforced Clostridium agar (Oxoid) after incubation for 3 days anaerobically at $30^{\circ} \mathrm{C}$ 189in anaerobic jars containing Anaerocult ${ }^{\circledR}$. Bacterial numbers were converted to $190 \log _{10}$ colony-forming units per gram sample (CFU/g sample) prior to statistical 191analyses.

\subsection{Statistical analysis}

1930ne-way analysis of variance of data was carried out using the SPSS 22 for 194Windows (SPSS Statistical software, Inc., Chicago, IL, USA) software package. 195Tukey's HSD test was used to compare treatment means when significant differences 196were found with the ANOVA. The significance level was always set to 0.05 .

\section{Results and discussions}

\subsection{Surface treatment of PE/PA packs}

199In a previous study Clarke et al. (2016) demonstrated that SO and AFV displayed the 200greatest antimicrobial efficacy against the tested bacterial strains; (Bacillus cereus, 201Pseudomonas fluorescens, Escherichia coli, Staphylococcus aureus and aerobic and 202anaerobic beef microflora) therefore, those antimicrobials were chosen for this study. $203 \mathrm{SO}$ and AFV were incorporated in beef gelatine solutions and coated onto the inner 204LDPE of the conventional vacuum PA/LDPE pouches 205

206Beef gelatin hydrophilic water solutions cannot be attached properly onto 207hydrophobic polyethylene surfaces. Polyethylene is by nature a hydrophobic 208material; therefore, it is necessary to modify the surface of the film prior to coating 209to improve wettability and achieve good adhesion (Robertson et al., 2014). There are 210several types of surface modification techniques used in the packaging industry for 211adhesion improvement of coatings, among others; corona treatment, chemical 212treatment or priming (Robertson., 2014) and plasma treatment. Cold plasma induces 213several chemical and physical processes within the plasma volume and on the 214plasma-polymer interface, which modify surface properties (Pankaj et al., 2014). 215Therefore DBD plasma treatment of the LDPE surface was applied in order to 216increase the affinity with the gelatine solution. In order to investigate the surface 217energy properties of the PE before and after plasma treatment the contact angle was 
218measured (Yuan and Lee, 2013). The contact angle is defined as the angle $\Theta$ formed 219by the intersection of the liquid interface and the surface interface (fig. 2).

220A significant $(\mathrm{p}<0.05)$ decrease in the contact angle for both test liquids (water and 221ethylene glycol) was observed after plasma treatment of the surface of LDPE (Table 2221A). The untreated LDPE film had a water contact angle $\Theta$ of $97.7^{\circ}$, thereby 223showing the hydrophobic nature of the film. After plasma treatment at $80 \mathrm{kV}$ for $60 \mathrm{~s}$ 224the water contact angle decreased to $59.9^{\circ}$, thus demonstrating an increase in the 225surface hydrophilicity. Contact angle was also measured during film storage to 226identify if the hydrophobic nature of the film was recovered. A significant $(P<0.05)$ 227increase of the water contact angle was noticed during film storage, reaching a 228contact angle of $73.6^{\circ}$ after $75 \mathrm{hr}$ storage at room temperature. The total surface free 229energy $\left(\gamma^{\text {tot }}\right)$ increased significantly $(P<0.05)$ due to a significant increase in the polar 230component $\left(\gamma^{p}\right)$ and consequently, a decrease in the dispersive component $\left(\gamma^{d}\right)$ (Table 2311B). During film storage, an increase in the dispersive component and decrease in 232the polar component was also observed.

233

234Table 1: Contact angle (A) and surface free energy of DBD plasma treated PE film during 235storage

\begin{tabular}{cccc} 
A. Contact angle & & & \\
\hline Sample & Storage time $(\mathrm{hr})$ & Water $\left(^{\circ}\right)$ & Ethylene glycol $\left(^{\circ}\right)$ \\
\hline Control (LDPE) & 0 & $97.7 \pm 1.5$ & $78.2 \pm 1.7$ \\
$80 \mathrm{kV}-60 \mathrm{~s}$ & 0 & $59.9 \pm 3.0$ & $50.9 \pm 2.7$ \\
$80 \mathrm{kV}-60 \mathrm{~s}$ & 30 & $66.9 \pm 1.4$ & $37.3 \pm 0.4$ \\
$80 \mathrm{kV}-60 \mathrm{~s}$ & 53 & $66.6 \pm 0.7$ & $44.1 \pm 3.6$ \\
$80 \mathrm{kV}-60 \mathrm{~s}$ & 75 & $73.6 \pm 0.2$ & $55.2 \pm 0.1$
\end{tabular}

236

B. Surface free energy

\begin{tabular}{ccccc}
\hline Sample & Storage time $(\mathrm{hr})$ & $\gamma^{\text {tot }}[\mathrm{mN} / \mathrm{m}]$ & $\gamma^{\mathrm{d}}[\mathrm{mN} / \mathrm{m}]$ & $\gamma^{\mathrm{p}}[\mathrm{mN} / \mathrm{m}]$ \\
\hline Control (LDPE) & 0 & 18.2 & 14.5 & 3.7 \\
80kV-60s & 0 & 43.2 & 5.2 & 38.0 \\
80kV-60s & 30 & 38.7 & 23.0 & 15.7 \\
80kV-60s & 53 & 36.4 & 16.2 & 20.2 \\
80kV-60s & 75 & 30.5 & 13.1 & 17.4
\end{tabular}

238The results presented in this study clearly demonstrate the importance of DBD 239plasma treatment of PE films before coating for making a more homogenous 240antimicrobial coating on the surface of film. However, hydrophobic nature recovery 
241of the DBD plasma treated film during storage indicated that the coating process 242must be carried out soon after DBD plasma treatment. In the present study, for 243optimum adhesion and to obtain a more homogeneous film coating LDPE films were 244coated with the antimicrobial coating within $24 \mathrm{hr}$ of plasma treatment.

\section{2. pH values of packaged beef steaks}

246The effects of active antimicrobial treatments on the $\mathrm{pH}$ values of vacuum packaged 247beef steaks are shown in Table 2. The initial $\mathrm{pH}$ of fresh beef in the control packs 248was 5.5. Following the immediate vacuum packaging of steaks using both AFV and 249SO antimicrobial films, steak pH values significantly $(\mathrm{p}<0.05)$ increased within 24 250hrs of packaging. This increase in $\mathrm{pH}$ was most likely due to the initial $\mathrm{pH}$ of the 251antimicrobial coating film forming solutions which were 6.2 and 6.5, respectively. A 252similar effect was reported by Emiroğlu et al. (2010) who applied soy protein-based 253edible films (pH 10.0) to beef patty surfaces.

254However, in our study, the increased meat $\mathrm{pH}$ was only short-lived, possibly due to 255the initial $\mathrm{pH}$ of the beef having a neutralising effect on the overall $\mathrm{pH}$, thus the $\mathrm{pH}$ 256decreased quickly and normalised meat $\mathrm{pH}$ values were maintained throughout the 257storage time. The decrease in steak $\mathrm{pH}$ in antimicrobially-treated packs could be 258attributed to the presence of lactic acid bacteria (LAB). Strains of LAB can produce 259fermentation products in the form of organic acids which may result in a decrease in 260pH over time (Jones, 2004; Sakala et al., 2002). LAB strains of bacteria are known 261to be resistant to many antimicrobial substances (Han et al., 2014; Fik \& 262Leszczyska-Fik, 2007; Emiroğlu et al. 2010). In our study, we observed the 263successful growth of LAB in our antimicrobially-treated packs (see next section for 264greater detail).

265The opposite trend was observed for the control samples, where a slight increase in $266 \mathrm{pH}$ was observed until day 23 of storage. An increase in $\mathrm{pH}$ may have been caused 267by the high levels of psychrotrophic bacteria present during the initial days of 268storage. Psychrotrophic bacteria produce volatile amine and ammonia which can 269increase $\mathrm{pH}$ levels and that the accumulation of those metabolites produced by 270psychotropic bacteria growth may cause pH increase (Cortez-Vega et al., 2012). 
272Table 2. The changes of $\mathrm{pH}$ on vacuum packaged beef steaks held in control and antimicrobially273active packaging during chilled storage

\begin{tabular}{cccc}
\hline Storage days & Control & AFV & SO \\
\hline 1 & $5.5 \pm 0.01^{\mathrm{a}}$ & $6.4 \pm 0.02^{\mathrm{b}}$ & $6.4 \pm 0.01^{\mathrm{b}}$ \\
7 & $5.5 \pm 0.05^{\mathrm{a}}$ & $5.6 \pm 0.06^{\mathrm{ab}}$ & $5.7 \pm 0.03^{\mathrm{b}}$ \\
14 & $5.5 \pm 0.04^{\mathrm{a}}$ & $5.6 \pm 0.02^{\mathrm{b}}$ & $5.7 \pm 0.01^{\mathrm{b}}$ \\
23 & $5.7 \pm 0.04^{\mathrm{a}}$ & $5.6 \pm 0.02^{\mathrm{ab}}$ & $5.7 \pm 0.01^{\mathrm{b}}$ \\
29 & $5.6 \pm 0.02^{\mathrm{a}}$ & $5.6 \pm 0.02^{\mathrm{a}}$ & $5.7 \pm 0.05^{\mathrm{b}}$ \\
36 & $5.5 \pm 0.02^{\mathrm{a}}$ & $5.5 \pm 0.02^{\mathrm{a}}$ & $5.6 \pm 0.01^{\mathrm{b}}$
\end{tabular}

$274^{\mathrm{a}, \mathrm{b}}$ Mean values and standard deviations in the same row with different superscripts are significantly 275different $(p<0.05)$.

\subsection{Microbiological analysis}

277Initial TVC and psychrotrophic bacteria counts for control, AFV and SO packaged 278beef steak samples after day 1 of storage were reported as $3.18 \log , 2.70 \log$ and 3.00 279log CFU/g, respectively, indicating that beef steaks were of good microbiological 280quality (Fig. 3a). In general, during storage independent of the packaging system 281used, the TVC numbers increased; however, throughout storage higher growth was 282noticed in control samples compared to samples stored in antimicrobially-coated 283pouches. Microbiological standards and guidelines give guidance on the types of 284microorganism and their number that can be considered acceptable or unacceptable 285or unsafe in a food product. The following recommended microbiological limits are 286applied for raw meat: Aerobic plate counts: $m=10^{6}$ (CFU/ g of meat) (acceptable 287limit) and $\mathrm{M}=10^{7}$ (CFU/g of meat)) (Unacceptable limit); $E$. coli: $\mathrm{m}=50 \mathrm{CFU} / \mathrm{g}$ of 288meat (acceptable limit) and $\mathrm{M}=500 \mathrm{CFU} / \mathrm{g}$ of meat), (European Commission, 2007; 289ICMSF, 1986). For this study the limit of acceptability was set to 6 log (CFU/g of 290meat) and E. coli $50 \mathrm{CFU} / \mathrm{g}$ of meat. Microbiological enumeration for TVC, 291psychrotrophic bacteria, LAB, and TAB bacteria during storage are shown in figure 2923.

293Throughout storage, significantly $(P<0.05)$ lower bacterial counts were observed in 294samples that were vacuum packed in packs coated with antimicrobial SO compared 295to samples that were vacuum packed with control films or films coated with 296antimicrobial AFV. The results found in this study is in agreement with results 297reported previously by Clarke et al. (2016) in which SO was the most effective 298antimicrobial against pure cultures of B. cereus, Ps. fluorescens, E. coli, S. aureus 
299and the aerobic and anaerobic microflora from beef steaks as it had the lowest MIC 300compared to the other antimicrobials tested. The authors also found that beef-derived 301gelatin films containing SO enhanced the mechanical properties and water vapour 302permeability when compared to control gelatin films.

303The limit of acceptability was reached at day 27, 35 and 42 for samples that were 304vacuum packed with control, AFV coated antimicrobial or SO antimicrobially coated 305films, respectively. Therefore, beef vacuum packed with the antimicrobial coating 306containing AFV or SO stayed within acceptability levels 33 or 55\% longer, 307respectively compared to samples that were vacuum packed with control films.

308Significantly $(P<0.05)$ slower growth of psychrotrophic bacteria was noticed in beef 309steaks that were vacuum packed with SO coated LDPE films compared to beef 310steaks vacuum packed with AFV coated LDPE films or control films (Fig. 3B). 311However, at the end of storage, no significant differences were noticed between the 312samples that were vacuum packed with AFV or SO coated LDPE films.

$313 S O$ films significantly $(\mathrm{p}<0.05)$ reduced bacterial counts compared to control 314samples for psychrotrophic bacteria from day 14 until the end of testing, AFV treated 315packaging only significantly $(\mathrm{p}<0.05)$ reduced bacterial counts as compared to 316control packaging on day 21 of testing (Fig. 3B) No significant differences were 317observed at the end of the testing period between AFV and SO films for 318psychrotrophic bacteria.

319A similar pattern was observed on TAB and LAB counts. SO coated LDPE films 320significantly $(\mathrm{p}<0.05)$ reduced TAB and LAB bacterial counts compared to steaks 321that were vacuum packed with AFV coated LDPE films or control films from day 14 322onwards until the end of testing and storage period (Fig. 3C, 3D). Clostridium spp. 323was absent throughout the storage period, coliforms were present on day 35 of 324testing and were slightly higher in treatment samples, however, levels remained 325within acceptable limits $\left(5 \times 10^{2}\right)$ throughout the testing period. Similar results were 326reported in a study conducted by Brightwell et al, (2009) who compared the 327microflora of peroxyacetic acid treated and vacuum-packed beef. Enterobacteriaceae 328counts were first detected on week 6 of testing and were found to be higher in treated 329versus untreated samples, with levels of Enterobacteriaceae being 25\% and 11\%, 330respectively, of the total microflora present. 
3324. Conclusion

333Beef gelatin as a carrier and coating polymer was used to successfully develop 334antimicrobial gelatine coated LDPE films by coating the inner PE layer of 335conventional PA/LDPE laminated films after surface activation using cold plasma 336treatment. The coated antimicrobials tested demonstrated different degrees of 337effectiveness against bacterial species evaluated on beef steaks. Based on the limit of 338acceptability in terms of total aerobic counts and E. coli, the antimicrobial AFV and $339 S O$ coated films significantly prolonged the shelf life of beef steaks by 33 or $55 \%$, 340respectively, compared to samples that were vacuum packed using control film 341samples. Overall, SO or AFV have the potential of being used as effective 342antimicrobials for antimicrobial active packaging applications for muscle-based food 343products.

344

\section{Acknowledgement}

346The funding for this research was provided by the Food Institutional Research 347Measure (FIRM) project entitled 'Packaging and chilling technologies to enhance 348meat quality and safety' (Pac-Chill-Tech) (11/F/033) under the National 349Development Plan administered by the Department of Agriculture, Fisheries and 350Food, Ireland.

351

352

353

354

355

356References 
357Brightwell, G., Clemens, R., Adam, K., Urlich, S., Boerema, J. 2009. Comparison of 358culture-dependent and independent techniques for characterisation of the microflora 359of peroxyacetic acid treated, vacuum-packaged beef. Food Microbiology. 3, 383-288.

360Campos, C.A., Gerschenson, L.N., Flores, S.K. 2011. Development of edible films 361and coatings with antimicrobial activity. Food and Bioprocess Technology. 4, 849362875.

363Clarke, D., Molinaro S., Tyuftin A., Bolton D., Fanning S., Kerry J.P. 2016. 364Incorporation of commercially-derived antimicrobials into gelatin-based films and 365assessment of their antimicrobial activity and impact on physical film properties. 366Food Control, 64, $202-211$.

367Cortez-Vega, W.R., Pizato, S., Prentice, C. 2012. Quality of raw chicken breast 368stored at $5{ }^{\circ} \mathrm{C}$ and packaged under different modified atmospheres. Journal of Food 369Safety. 32, 360-368.

370Cuq, B., Gontard, N., Guilbert, S. 1995. Edible films and coatings as active layers, 371in: Cuq, B., Contard, N., Guilbert, S. (Eds.), Active food packaging. Springer, 111372142.

373Cutter, C.N. 2006. Opportunities for bio-based packaging technologies to improve 374the quality and safety of fresh and further processed muscle foods. Meat science. 74, 375131-142.

376EC (2007). Commission Regulation No 1441/2007 of 5 December 2007 amending 377Regulation (EC) No 2073/2005 on microbiological criteria for foodstuffs. Official 378Journal of the European Union. L322, 12-29.

379Emiroğlu, Z.K., Yemiş, G.P., Coşkun, B.K., Candoğan, K. 2010. Antimicrobial 380activity of soy edible films incorporated with thyme and oregano essential oils on 381fresh ground beef patties. Meat Science. 86, 283-288.

382Fik, M, Leszczyska-Fik A. 2007. Microbiological and sensory changes in minced 383beef treated with potassium lactate and sodium diacetate during refrigerated storage. 384International Journal of Food Properties, 10 (3), pp. 589-598. 
385Gómez-Estaca, J., de Lacey, A.L., Gomez-Guillen, M.E., Montero, P. 2010. 386Biodegradable gelatin-chitosan films incorporated with essential oils as 387antimicrobial agents for fish preservation. Food Microbiology. 27, 889-896.

388Gill, A.O., Delaquis, P., Russo, P., Holley, R.A. 2002. Evaluation of antilisterial 389action of cilantro oil on vacuum packed ham. International Journal of Food 390Microbiology. 73, 83-92.

391Han C., Wang. J, Li. Y.,Lu. Cui Y. 2014. Antimicrobial-coated polypropylene films 392with polyvinyl alcohol in packaging of fresh beef. Meat Science 96 issue 2, pp 901393907.

394Hanani, N.Z.A., Roos, Y.H., Kerry, J.P. 2012. Use of beef, pork and fish gelatin 395sources in the manufacture of films and assessment of their composition and 396mechanical properties. Food Hydrocolloids. 29, 144-151.

397Hanani, N.Z.A., Beatty, E., Roos, Y.H., Morris, M.A., Kerry, J.P. 2012. Manufacture 398and characterization of gelatin films derived from beef, pork, and fish sources using 399twin screw extrusion. Journal of Food Engineering. 113, 606-614.

400Hanani, N.Z.A., McNamara, J., Roos, Y.H., Kerry, J.P. 2013. Effect of plasticizer 401content on the functional properties of extruded gelatin-based composite films. Food 402Hydrocolloids. 31, 264-269.

403Jones, R.J. 2004. Observations on the succession dynamics of lactic acid bacteria 404populations in chill-stored vacuum-packaged beef. International Journal of Food 405Microbiology. 90, 273-282.

406Kerry, J., Paul, B., 2008. Smart Packaging Technologies for Fast Moving Consumer 407Goods, in: Kerry, J.P. (Eds.), Front Matter. John Wiley \& Sons, Ltd. pp. 1-26.

408Kerry, J.P. 2012. Advances in meat, poultry and seafood packaging, in: Kerry, J.P 409(Eds.), A volume in Woodhead Publishing Series in Food Science, Technology and 410Nutrition. Elsevier, pp. 720.

411Millette, M., Le, T.C., Smoragiewicz, W. 2007. Inhibition of Staphylococcus aureus 412on beef by nisin-containing modified alginate films and beads. Food Control. 18, 413878-884. 
414Morsy, M.K., Khalaf, H.H., Sharoba, A.M., El-Tanahi, H.H. 2014. Incorporation of 415Essential oils and Nanoparticles in Pullulan Films to Control Foodborne Pathogens 416on Meat and Poultry Products. Journal of food science. 79, 675-684.

417Molinaro, S., Cruz-Romero, M., Sensidoni, A., Morris., M., Lagazio, C., Kerry, J.P. 4182015. Combination of high-pressure treatment, mild heating and holding time effects 419as a means of improving the barrier properties of gelatin-based packaging films 420using response surface modelling. Innovative Food Science \& Emerging 421Technologies. 30, 15-23.

422Muriel-Galet, V., Cerisuelo, J.P., López-Carballo, G., Lara, M., Gavara, R., 423Hernández-Muñoz, P. 2012. Development of antimicrobial films for microbiological 424control of packed salad. International Journal of Food Microbiology. 157, 195-201.

425Pankaj, S.K., Bueno-Ferrer, C., Misra, N.N. 2014. Applications of cold plasma 426technology in food packaging. Trends in Food Science \& Technology. 35, 5-17.

427Quintavalla, S., Vincini, L. 2002. Antimicrobial food packaging in meat industry. 428Meat Science. 62, 373-380.

429Robertson, G.J., 2014. Food packaging: Encyclopedia of Agriculture and Food 430Systems, 2014, pp 232-249

431Sakala. R.M., Hayashidani. H, Kato. Y, Hirata. T, Makino Y, Fukushima A, 2002 432Change in the composition of the microflora, on vacuum-packed beef during chiller 433storage International Journal of Food Microbiology, 74 , pp. 87-99

434Suppakul, P., Sonneveld, K., Bigger, S.W., Miltz, J. 2008. Efficacy of polyethylene435based antimicrobial films containing principal constituents of basil. LWT-Food 436Science and Technology. 41, 779-788.

437Wang, L., Liu, L., Holmes, J., Kerry, J.F., Kerry, J.P. 2007. Assessment of film438forming potential and properties of protein and polysaccharide-based biopolymer 439films. International Journal of Food Science and Technology. 42, 1128-1138.

440Yingyuad, S., Ruamsin, S., Reekprkhon, D., Douglas, S., Pongamphai, S., 441Siripatrawan, U. 2006. Effect of chitosan coating and vacuum packaging on the 442quality of refrigerated grilled pork. Packaging Technology and Science. 19, 149-157. 
443Yuan, Y, Lee T. R. Contact Angle and Wetting Properties.Chapter in Surface Science 444Techniques. Springer Series in Surface Sciences. 51, 3-34. 


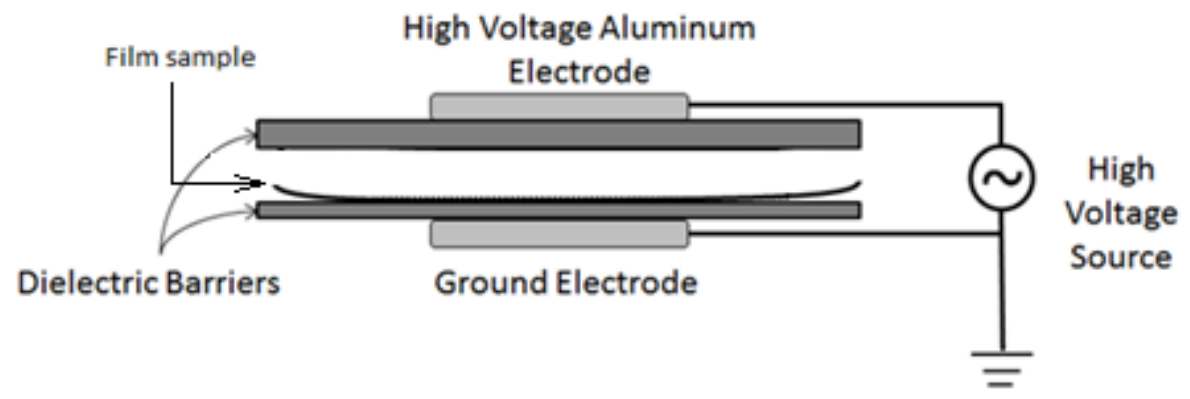

Fig. 1. Schematic representation of the experimental setup for plasma treatment.

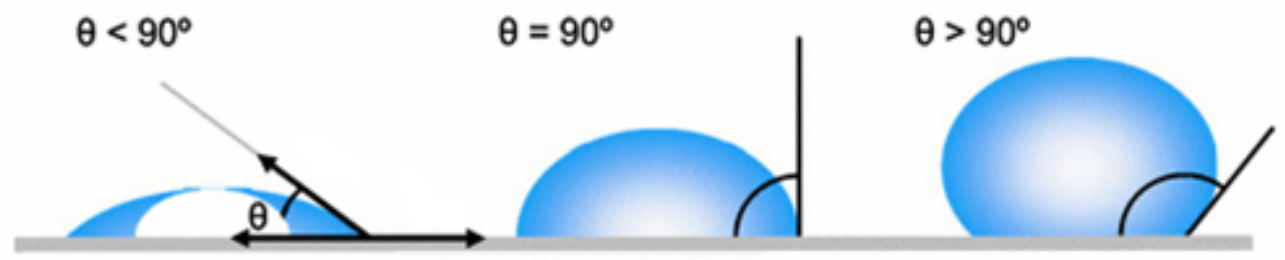

Fig. 2. Contact angle formed by sessile liquid drops on a smooth homogeneous solid surface (hydrophilic surface $\left(\theta<90^{\circ}\right)$ hydrophobic surface $\left(\theta>90^{\circ}\right)$, (Yuan and Lee, 2013).
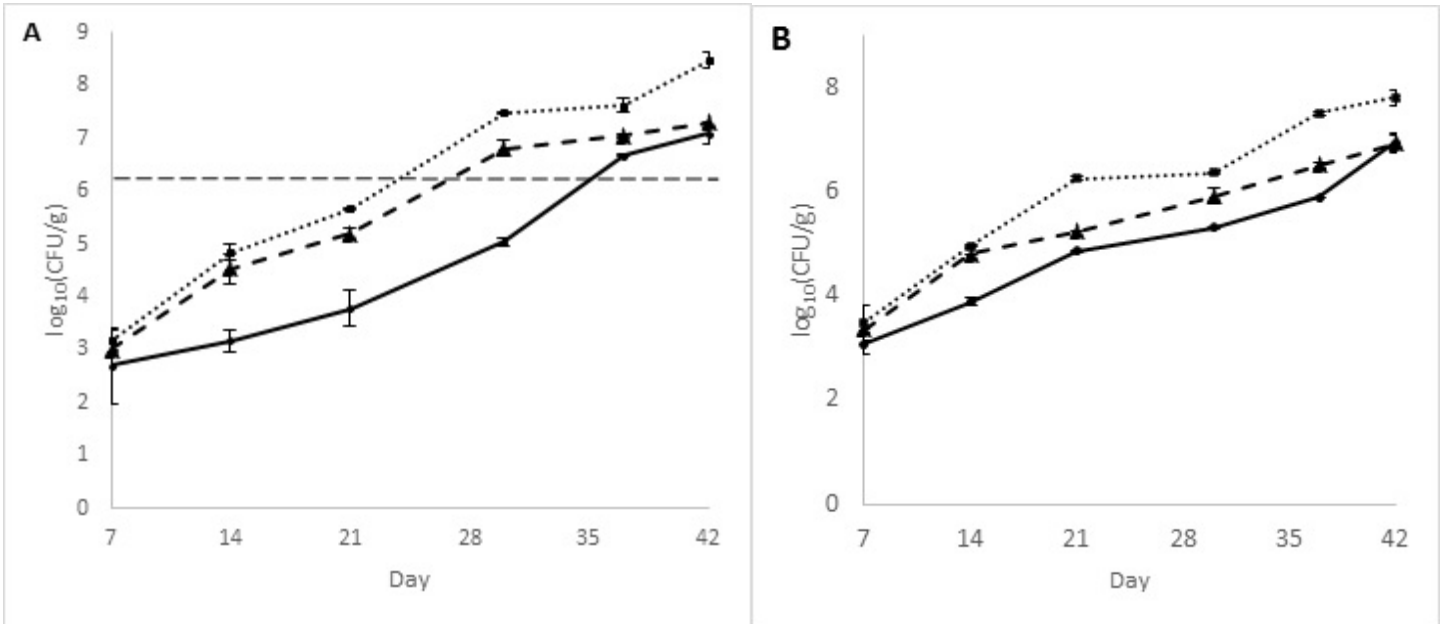

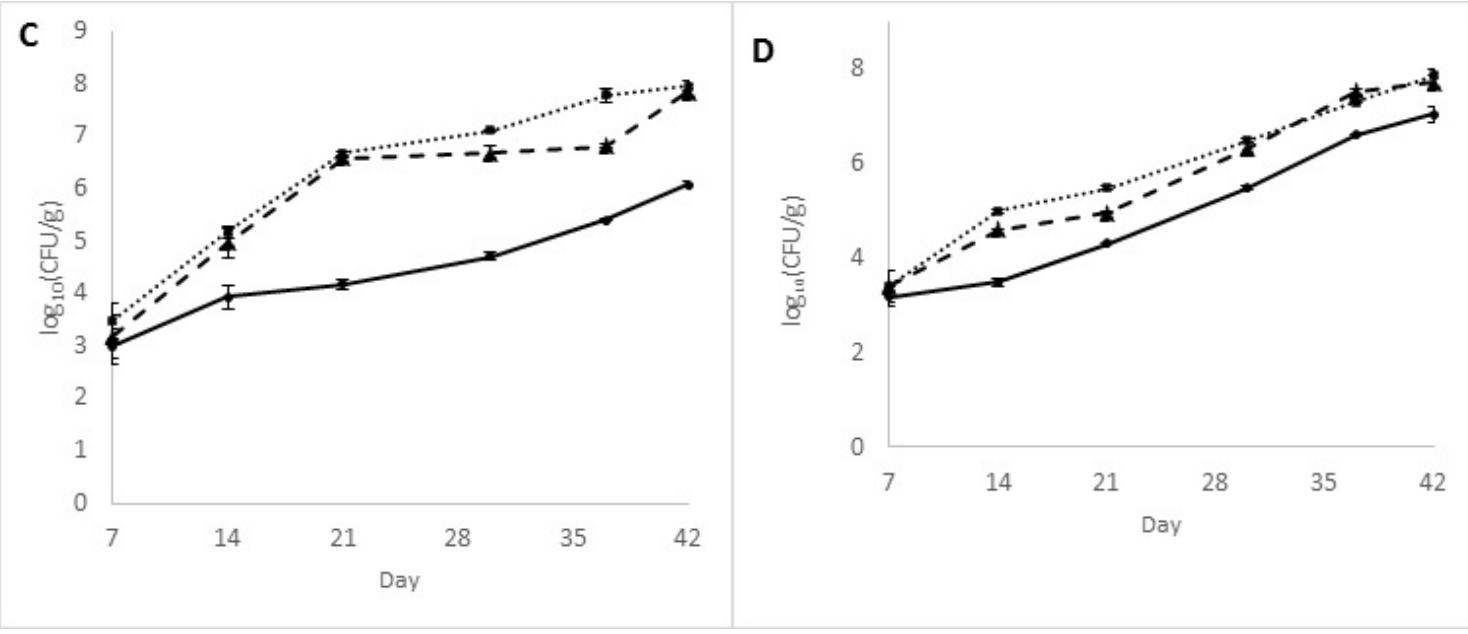

Fig. 3. Changes in (A) Total viable counts, (B) Psychrotrophic bacteria (C) Lactic acid bacteria, and (D) Total anaerobic bacteriaduring chilled storage of beef steaks vacuum-packaged using control (...) or antimicrobiallyactive (---) AFV or (-) SO packaging films. The dotted line in (A) indicates the limit of acceptability. Bars represent standard deviation of three independent samples and may be hidden by symbols when small. 
- Beef gelatin was successfully coated on plasma treated polyethylene surface

- Auranta FV and Sodium octanoate coated films prolonged the shelf life of beef cuts

- $\quad \mathrm{AFV}$ and SO potentially can be used in antimicrobial active packaging 
Surface attachment of active antimicrobial coatings onto conventional plastic-based laminates and performance assessment of these materials on the storage life of vacuum packaged beef sub-primals.

David Clarke ${ }^{1}$, Andrey A. Tyuftin ${ }^{1}$, Malco C. Cruz-Romero, ${ }^{1}$ Declan Bolton ${ }^{2}$, Seamus Fanning ${ }^{3}$, Shashi K. Pankaj ${ }^{4}$, Carmen Bueno-Ferrer ${ }^{4}$, Patrick J. Cullen ${ }^{4}$, Joe P. Kerry*1

${ }^{1}$ Food Packaging Group, School of Food \& Nutritional Sciences, University College Cork, College Road, Cork, Ireland

${ }^{2}$ Food Safety Department, Teagasc Food Research Centre, Ashtown, Dublin 15, Ireland

${ }^{3}$ School of Public Health, University College Dublin, Belfield, Dublin 4, Ireland.

${ }^{4}$ BioPlasma Research group, School of Food Science and Environmental Health,

Dublin Institute of Technology, Cathal Brugha Street, Dublin 1, Ireland

*corresponding author

Tel: +353(0)21 4903798

Fax: +353 (0)21 4276318

E-mail: Joe.Kerry@ucc.ie

KEYWORDS: Gelatin films; Edible coatings; Antimicrobials; Antimicrobial Active Packaging; Food Packaging; Plasma treatment 